\title{
Legislative Councilors' Perceptions of Gambling Expansion and Responsible Gambling Practices in Hong Kong
}

\author{
Irene Lai Kuen Wong*, Yuk Wa Chui, Yee Shan Yue \\ Department of Applied Social Sciences, The Hong Kong Polytechnic University, \\ Hong Kong \\ *Corresponding author; email: ssilkw@inet.polyu.edu.hk
}

\begin{abstract}
This study investigates the Legislative Councilors' perceptions of gambling expansion and responsible gambling practices in Hong Kong. Employing quota sampling strategies, fourteen councilors were recruited to attend a 30-minute semi-structured interview. The results showed that many respondents $(64.3 \%)$ rejected further expansion of legalized gambling in Hong Kong. Only two interviewees explicitly supported further gambling liberalization (e.g. casino gambling or increases in horse races). While the opponents were concerned about the negative impacts associated with legalized gambling activities, the proponents emphasized the economic benefits of further gambling expansion. Factors that might have influenced the councilors' views on gambling expansion were identified: individual gambling attitudes and past experience in gambling participation, knowledge about excessive gambling, and views on individual versus social responsibility for gambling problems. Few interviewees considered that gamblers were solely responsible for their actions, difficulties and for their problem-solving endeavors. Most agreed that both the government and gambling operators have a very important role to play in addressing problem gambling, and would like to urge these key stakeholders to minimize gambling-related harms through improving responsible gambling practices. The study results have implications for gambling legislation, policy, and research.
\end{abstract}

Key words Harm Minimization · Problem Gambling · Responsible Gambling

\section{Introduction}

Gambling is a popular recreational activity in Hong Kong. It was estimated that $80 \%$ of the general population had participated in gambling activities (University of Hong Kong, 2005; Wong \& So, 2003). With the exception of 
mahjong parlors, the Hong Kong Jockey Club (HKJC), a not-for-profit organization, has been the sole legal gambling provider since 1884. Legal gambling opportunities are restricted to playing mahjong at authorized venues, horse racing, soccer betting and the Mark Six lottery operated by the HKJC. Although the government policy is to restrict gambling, the number of Mark Six draws and horse race days has increased substantially in the past three decades. For example, Mark Six draws have increased from once a week in the 1970s to three times a week at the time of writing. Horse racing has also expanded from a weekly activity to twice a week. In 2009, the Legislative Council approved the HKJC's application for a further increase of five horse racing days and fifteen overseas horse races. Hence, even without liberalizing other forms of gambling, opportunities for the citizens of Hong Kong to participate in legal gambling have increased significantly.

There are both benefits and costs associated with providing regulated gambling activities. Legalized gambling can generate tax revenues, increase employment, provide enjoyment, expand entertainment opportunities, and enhance tourism (e.g. Chadbourne et al., 1997; Filby \& Harvey, 1988; Gazel, 1998; National Institute of Economics and Industry Research, 2003; Productivity Commission, 1999). The HKJC contributed HK\$13.62 billion in tax and betting duty in the 2009/ 2010 fiscal year (Hong Kong Jockey Club, 2011). The HKJC is the largest single tax payer in Hong Kong, and with a staff population exceeding 26,000, it is also one of the biggest employers. Apart from economic interests, the government considers that it has an obligation to meet public demand for gambling. This is seen as providing an alternative to illegal gambling which is widely regarded as associated with criminal activity.

Legalized gambling also causes harmful impacts to individuals, families, and society. Adverse social consequences include underage and problem gambling, increased crime, legal problems, loan sharking, divorce and disrupted social relationships, suicides and psychiatric problems (e.g. Bergh \& Kuhlhorn, 1994; Hong Kong Polytechnic University, 2001; Leung et al., 2010; Lorenz \& Yaffee, 1989; Marshall \& Wynne, 2003; Wong, 2010). Common negative economic effects are gambling debts, pawning of goods, bankruptcy, loss of productivity, unemployment, displacement effects of gambling, and increased expenditure to offset negative externalities (e.g. Dickerson, et al, 1995; Fong et al., 2011; Hong Kong Polytechnic University, 2001; National Institute of Economics and Industry Research, 2003; Siegel \& Anders, 1999).

In Hong Kong, there is heightened public concern about the detrimental impacts of legal gambling, especially after legalization of soccer betting in 2003. Although the prevalence of pathological gambling in the adult population seems to be stable (1.8-2\%) over the last decade (Hong Kong Polytechnic University, 2008; University of Hong Kong, 2005; Wong \& So, 2003), disordered gambling among the underage is becoming more of an issue. The prevalence of underage pathological gambling has increased from 2.6\% in 2001 (Hong Kong Polytechnic University, 2001) to 3.2\% in 2004 (Wong \& So, 2004) and 3.4\% in 2008 (Wong, 2010).

Under the leadership of pressure groups, there has been an increasing demand for strict regulation and responsible provision of gambling since the turn of the century (Wong, 2006). Problem gambling became a public health issue, and 
debates on how to strike the balance between public health interests and economic benefits continue (Wong, 2006). In order to meet changing community expectations, gambling operators and the government have to develop responsible gambling initiatives.

In many western jurisdictions, responsible gambling policies and practices have been developed to prevent or minimize potential gambling-related harms (Blaszczynski, et al., 2004, 2008). Customers are also allowed to make informed decisions about their participation in gambling. Hing (2001) categorized responsible gambling programs into harm minimization and customer protection strategies. Examples of the former include self-exclusion options, prohibiting credit gambling and providing a cooling off period after big wins. Examples of customer protection strategies range from responsible promotional materials to information on gambling products. However, the efficacy of each of these strategies has not been extensively verified (Hing, 2001; McMillen \& McAllister, 2000).

Problem gambling is not a new phenomenon in Hong Kong but responsible gambling practices did not exist until the Ping Wo Fund (contributed by the HKJC) was set up in 2003. Since then, efforts to develop and implement responsible gambling strategies have been made primarily by the HKJC (e.g. signs, information about helpline, and providing financial support for gambling counseling). However, evaluation of the efficacy of these programs has never been undertaken by an independent assessor, and the pressure for further improvement remains. Having little awareness of these socially responsible practices in gaming operations, operators of mahjong houses are not enthusiastic to adopt similar measures. Pressure groups usually request the HKJC to improve its responsible gambling practices, neglecting the role for mahjong gambling providers.

\section{Research purpose}

In Hong Kong, the Legislative Council exercises many influential functions including enacting laws, approving taxation, and raising questions on Government's work. Obviously, councilors play an important role in passing gambling legislation and making regulations on responsible gaming. The HKJC has to seek the councilors' support in any expansion of gambling activities. Little research has been conducted on responsible gambling in Hong Kong. The study attempts to fill this research gap. It examines the Legislative Councilors' perception of the benefits and costs of legal gambling activities and local responsible gambling practices. The research results have implications for gambling policy, legislation, and research.

\section{Method \\ Procedures}

From February to April 2009, letters outlining the research objectives were sent to all the sixty Legislative Councilors. Using quota sampling strategies (De Vaus, 1995), the researchers successfully contacted 22 councilors via telephone and invited them to participate in the study. Fourteen councilors eventually attended a 30-minute semi-structured interview, yielding a response rate of $63.3 \%$. The chief reason given for refusal for the interview was being too busily engaged in work-related duties $(80 \%)$. 
With the exception of two telephone interviews, the remaining 12 interviews were conducted face-to-face by at least two researchers who worked in a team. Ten interviews were audio-recorded whereas notes were taken in the other interviews. Thematic analysis was conducted to detect common themes derived from the interviews (Miles \& Huberman, 1994).

\section{Participants}

Employing quota sampling techniques, a quota matrix depicting the most important feature of the target respondents (i.e. membership of political parties) was created before subject selection. Three quotas were designed based on the proportion of council seats held (Legislative Council, 2009). The sample $(N=14)$ was composed of five councilors who were not affiliated with a particular political party (35.7\%), five Pan-Democrats (35.7\%), and four Pro-Government members (28.6\%). All declared that their views expressed in the study did not represent the standpoints of any party.

There were ten men and four women. Eight participants were in the middle years (36-54 years), four were of retirement age (60 years or above), and two were under 35 years. Majority completed a university degree $(n=10)$.

\section{Instruments}

After obtaining consent for the interview, the researchers used a semi-structured interview guide to collect data. The interviewers asked questions regarding the councilors' opinions on the perceived impacts of legal gambling and further gambling expansion, and the roles played by gambling operators and government in addressing problem gambling and protecting the gambling public. The respondents were also asked to comment on current responsible gambling practices.

\section{Results}

\section{Increasing social acceptance of legalized gambling}

Many respondents $(57.1 \%)$ commented on the increasing acceptance of legalized gambling activities in Hong Kong, particularly among juveniles $(50 \%)$ since soccer betting had been regularized in 2003. Four councilors remarked that both legal and illegal gambling, not only restricted to soccer betting, had become more popular since then. Problem gamblers' family members approached their offices for help, and community leaders in their districts had also expressed concerns about the proliferation of gambling involvement and gambling problems.

At least half of the interviewees noted that teens and young adults were particularly attracted to soccer and sports betting. They agreed that soccer betting had become a 'trendy' recreation among youth after legalization of soccer betting. They expressed concern about the damaging consequences of adolescent problem gambling. They highlighted an array of gambling-related negative impacts, including impairment in physical and mental health, erroneous cognitions about money and success, over-reliance on luck and chance, erosion of core traditional values which advocate being industrious and thrifty, and fostering of behavior characterized by greed and risk taking. Several exclaimed that Hong Kong would not have bright prospects if young people were encouraged to seek wealth and 
recreation by gambling. Three councilors emphasized the importance of promoting youth resiliency and provision of health-enhancing entertainment options (e.g. music, sports, and physical exercise).

Four respondents stated that they did not have evidence on which to judge citizens' gambling attitudes and involvement since 2003. Most (70\%) agreed that regular empirical studies would provide reliable data on gambling behavior and problems.

\section{Supporters of gambling expansion}

Only two respondents supported further liberalization of gambling activities in Hong Kong (e.g. NBA matches and increasing the number of horse races). They indicated that they held an 'open' attitude towards having a casino in Hong Kong although the proposal had already been turned down by the government in China. They admitted that they were fond of gambling activities which were perceived as a challenge, quality entertainment, and a shortcut to acquire wealth. They described themselves as very skillful players.

Their justification for gambling expansion was increased revenues and other economic benefits (e.g. tourism and creation of jobs), expanding recreational opportunities, satisfying public demands for gambling, and counteracting illegal gambling outlets. They communicated apathetic attitude towards gamblers' difficulties. One remarked that he disliked seeing gamblers losing work incentives or creating trouble for their bosses, work-mates or families. Excessive gambling was seen as an individual's problem caused by lack of self-control or intelligence, poor gambling skills and knowledge, greed, ill luck, and irrational choices. In short, the view was that pathological gamblers should be responsible for their behavior and their distress.

\section{Opponents to gambling expansion}

Many respondents $(64.3 \%$ ) strongly disapproved of further gambling liberalization to meet fiscal needs or to pursue economic benefits. They requested government to weigh carefully the fiscal, moral, and community interests in any expansion application. The view was that government should never rely on gambling revenues or ignore the adverse economic and social consequences of pathological gambling.

Several (35.7\%) admitted having acquaintances, colleagues, or even relatives who had gambling problems. They were aware of the destructive impact of problem gambling on gamblers and the entire family. Gambling problems were reported to be associated with debts, loan sharking, bankruptcy, family disintegration, suicides, and psychiatric problems. They were more sympathetic to family members than to compulsive gamblers who were described as 'selfish and irresponsible'.

Although gamblers were seen as responsible for their actions and problems, it was felt by many $(57.1 \%)$ that government and gambling providers should also be responsible for creating and solving gambling-related problems. At least four opined that government had developed a partnership with the HKJC to stimulate growth in gambling opportunities. They expressed a strong desire to see government taking responsibility to address problem gambling and protect the general public. 


\section{Factors shaping councilors' attitudes towards gambling expansion}

With the exception of two supporters of gambling expansion, and four who were not explicit in their views about it, most disapproved of further gambling liberalization. Factors that might have influenced councilors' views were identified: gambling attitudes, past experiences in gambling participation, knowledge on problem gambling, and their view on individual versus social responsibility in creating problem gambling.

\section{Current responsible gaming strategies implemented by gambling providers}

The majority of those interviewed (64.3\%) agreed that gaming operators had a very important role to play in addressing excessive gambling. They commented that the gambling operators were rich, particularly the HKJC but they had not taken sufficient responsibility in customer protection and harm minimization in gaming. They were keen to see the gambling operators shoulder more responsibility for prevention of gambling problems through implementing responsible gambling strategies.

Some of the HKJC's responsible gambling measures were more readily identified by the respondents. These included posters $(14.3 \%)$, warning messages $(28.6 \%)$, age restrictions $(57.1 \%)$, and information on helpline $(57.1 \%)$. Many interviewees were unaware of other strategies currently implemented by the HKJC such as information on excessive gambling, and provision of financial support for gambling intervention and research. Many were not aware of any responsible gambling measures adopted by operators of mahjong parlors.

Half of the respondents questioned the effectiveness of current measures, and suggested an efficacy evaluation to be conducted by an independent assessor $(42.9 \%)$. They also advised regular reviews of funding levels to ensure that sufficient resources were available for preventive, education, treatment, and recovery programs (50\%). Four councilors proposed a fixed proportion of gambling revenue should be taken to fund gambling research and various responsible gambling programs.

Suggestions on new harm minimization initiatives were also made: (a) soliciting financial support for self-help groups on the basis that recovered problem gamblers could provide outstanding models for other gamblers; (b) developing staff assistance programs and staff training programs on responsible gambling $(28.6 \%)$, with some $(21.4 \%)$ of the view that gaming employees were more susceptible to gambling problems; (c) providing 'self-exclusion' options to problem gamblers; (d) making it mandatory to provide information on safe gambling $(21.4 \%)$, risks and gambling-related harms at all gambling venues, online betting facilities $(35.7 \%)$ and promotional materials (14.3\%); and (e) placing an opinion box at all gambling stations to collect customers' opinions on responsible gambling policies and practices $(35.7 \%)$.

Only four councilors (21.4\%) were relatively more familiar with local gambling studies, and the prevalence of problem gambling. Many (42.9\%) were not familiar with local gambling research results although they recognized the importance of evidence-based data. 


\section{Government's role in responsible gambling practices}

Many councilors $(64.3 \%)$ agreed that the government should play a more active role to prevent and address the harmful impacts of gambling. They expected the government to develop a public health-enhancing gambling policy which would protect long-term social interests rather than short-term fiscal benefits $(42.9 \%)$. Some wanted to see the government improve responsible gambling legislation and regulation $(28.6 \%)$, to monitor the enforcement of responsible gambling strategies at all gaming venues $(28.6 \%)$, to raise the age for legal gambling participation from 18 to 21 years (21.4\%), to legislate to enforce self-exclusion programs, gaming staff training, and provision of information on helpline and services $(21.4 \%)$, and to ensure and provide sufficient funding for awareness promotion, prevention, treatment, and research $(50 \%)$.

Many $(57.1 \%)$ disagreed with the view that the government had done enough to prevent underage and excessive gambling. They questioned the efficacy of current measures $(50 \%)$. Regular efficacy evaluation of current preventive, educational and treatment programs was proposed $(42.9 \%)$. Four agreed that a commission should be set up to advise the government on gambling policies, responsible gambling legislation and practices, to co-ordinate and supervise the enforcement of harm minimization and customer protection strategies, and to allocate sufficient funds for different types of interventions $(28.6 \%)$.

Three councilors (21.4\%) expressed disappointment with governmental efforts in controlling illegal gambling, aggressive advertising, and promotional activities. They conceded that it was futile to implement any measures when gambling was being aggressively promoted as a popular, pleasurable, and harmless activity which might make players rich. Two adopted a very forward-looking perspective, advocating resiliency and a healthy life style built on regular exercise and sports. They stated that government should provide children and youth with more choices and opportunities to enjoy health-promoting forms of recreation.

\section{Discussion}

The study reveals that while the proponents of gambling expansion focused primarily on enjoyment, revenues and economic benefits, the opponents emphasized problem gambling and social ills. Previous studies indicate that there are both benefits and costs in legal gambling and its expansion. However, no comprehensive investigation on both benefits and costs has been conducted in Hong Kong. It is necessary to undertake a thorough evaluation of both positive and negative impacts, and such impact studies should be regular to reflect the changing social and gambling environment. Furthermore, if gambling opportunities have been expanded (e.g. casino gambling, NBA matches, or increases in race days), surveys should be conducted to gauge the prevalence of excessive gambling, and to detect potentially vulnerable groups.

In New South Wales, a social impact assessment has to be included in any application for expansion of gambling machines or activities (e.g. McMillen \& McAllister, 2000). The authors suggest that an assessment of social impact should be made in addition to fiscal benefit estimation prior to any application for gambling expansion in order to protect public health interests. Above all, long-term social, 
financial, health, and moral considerations should also be included in the decisionmaking process. It seems clear that benefits should always outweigh costs and potential harms in any legal gambling activity and its further expansion.

Most respondents were concerned about underage and problem gambling. Many urged the government and gambling operators to take a more active role in preventing gambling-related damages, and in protecting patrons and the public through integrating social responsibility programs within gaming operations. To date, preventive initiatives and helping responses initiated by these two key stakeholders have been modest. It is necessary to seek further involvement from these stakeholders across the entire range of remedial, preventative, educational, and research initiatives.

In order to meet international standards, harm minimization and patron protection objectives should be integrated into gambling policy and legislation. Currently, there is no responsible gambling legislation in Hong Kong, thus gambling operators enjoy the liberty of self-regulation. As a result, no standards for patron protection and harm minimization have been set, not to mention good practices. A report commissioned in Australia noted that self-regulatory approaches are less likely to be as effective as explicit regulatory requirements (Productivity Commission, 1999). The government in Hong Kong needs to introduce and impose clear legislative obligations on gambling operators who wish to create a sustainable gambling environment through the provision of responsible gaming programs.

Responsible gambling programs are new to many Asian regions. Key stakeholders need to collaborate in order to develop culturally appropriate practices and strategies to protect players and vulnerable groups (e.g. underage adolescents, and gaming employees) from the potential harms associated with gambling activities. Empirical studies are also needed to verify which strategies are practical and effective in which particular forms of gambling, and the reasons for this. Efficacy evaluations of current strategies can provide useful data for further improvement, and these reviews should be conducted regularly by independent assessors.

Many councilors pointed out the paucity of gambling studies in Hong Kong despite the significant growth in gambling revenues. More gambling research is needed to generate evidence-based information to inform policy and enhance legislative decisions. In many western jurisdictions, gambling research funds have been established, and these are contributed to by government and or gambling operators. Hong Kong would benefit from establishing a similar fund, with a view to funding local, empirical research on gambling issues. Ideally, both gambling operators and government would contribute to this research fund.

In this study, only fourteen councilors were interviewed. It is unlikely that the study results can be generalized to other Asian regions. Future research should recruit larger samples, and target other key stakeholders, such as government officials and policy-makers, gambling operators and employees, consumers, health service and treatment providers. It is hoped that with the establishment of a gambling research fund, more large-scale gambling studies will be conducted, including studies on responsible gambling practices. 


\section{Acknowledgments}

The authors wish to thank the counselors who participated in this study. The authors would also like to thank C. Y. Ho and V. Leung who assisted with data collection.

\section{References}

Bergh, C., \& Kuhlhorn, E. (1994). Social, psychological and physical consequences of pathological gambling in Sweden. Journal of Gambling Studies, 10, 275-285.

Blaszczynski, A., Ladouceur, R., \& Shaffer, H. J. (2004). A science-based framework for responsible gambling: The Reno model. Journal of Gambling Studies, 20, 301-317.

Blaszczynski, A., Ladouceur, R., Lia, N., \& Shaffer, H. J. (2008). Informed choice and gambling: Principles for consumer protection. Journal of Gambling Business and Economics, 2, 103-118.

Chadbourne, C., Walker, P., \& Wolfe, M. (1997). Gambling, economic development, and historic preservation. Chicago: American Planning Association.

De Vaus, D. A. (1995). Survey in Social Research. University College London: Allen and Unwin.

Dickerson, M., Allcock, C., Blaszczynski, A., Nicholls, B., Williams, J., \& Maddern, R. (1995). An examination of the socioeconomic effects of gambling on individuals, families, and the community including research into the costs of problem gambling to New South Wales. Sydney: Australian Institute for Gambling Research.

Filby, M. P., \& Harvey, L. (1988). Recreational betting: Everyday activity and strategies. Leisure Studies, 7, 159-172.

Fong, K. C., Fong, H. N., \& Li, S. Z. (2011). The social cost of gambling in Macao: before and after the liberalization of the gaming industry. International Gambling Studies, 11, 43-56.

Gazel, R. (1998). The economic impacts of casino gambling at the state and local levels. The Annals of the American Academy of Political and Social Science, 556, 66-84.

Hing, N. (2001). Changing the odds: A study of corporate social principles and practices in addressing problem gambling. Journal of Business Ethics, 33, 115-144.

Hong Kong Jockey Club. (2011). Retrieved from: http:/ / corporate.hkjc.com/ corporate/rgp/ english/index.aspx

Hong Kong Polytechnic University. (2001). A study on Hong Kong people's participation in gambling activities. Hong Kong: Hong Kong Polytechnic University.

Hong Kong Polytechnic University. (2008). Evaluative study on the impacts of gambling liberalization in nearby cities on Hong Kong people's participation in gambling activities and development of counseling and treatment services for problem gamblers. Hong Kong: Hong Kong Polytechnic University.

Legislative Council. (2009). Retrieved from: http://www.legco.gov.hk/general/chinese/ members/yr08-12/lwk.htm

Leung, K. C., Wong, I. L. K., Lau, K. M., \& Yeung, S. C. (2010). Stress, health and coping resources of Chinese pathological gamblers' spouses. Asian Journal of Gambling Issues and Public Health, 1, 61-74.

Lorenz, V. C., \& Yaffee, R. A. (1989). Pathological gamblers and their spouses: Problems in interaction. Journal of Gambling Behavior, 5, 113-126.

Marshall, K., \& Wynne, H. (2003). Fighting the odds. Statistics Canada Perspectives, December, $5-13$.

McMillen, J., \& McAllister, G. (2000). Responsible gambling: Legal and policy issues. Paper presented at the Third National Gambling Regulation Conference. Sydney.

Miles, M.B., \& Huberman, A.M. (1994). Qualitative data analysis: An expanded source book. Newbury Park, CA: Sage.

National Institute of Economics and Industry Research. (2003, July). The economic impact of gambling: A report for the Casino Community Benefit Fund. New South Wales. Department of Gaming and Racing. 
Productivity Commission. (1999). Australia's gambling industries (Report No. 10). Canberra: AusInfo.

Siegel, D., \& Anders, D. (1999). Public policy and the displacement effects of casinos: A case study of riverboat gambling in Missouri. Journal of Gambling Studies, 15, 105-121.

University of Hong Kong. (2005). A study on Hong Kong people's participation in gambling activities. Hong Kong: The University of Hong Kong.

Wong, I. L. K. (2006). Challenges confronting Asian gaming industry: Developing responsible gaming training and related initiatives. In Proceedings of An International Conference on Gaming Industry and Public Welfare 2006 (pp. 179-188). China Center for Lottery Studies, Peking University, Macao Polytechnic Institute and Institute for Tourism Studies.

Wong, I. L. K. (2010). Gambling behavior among underage adolescents in Hong Kong. Asian Journal of Gambling Issues and Public Health, 1, 47-60.

Wong, I. L. K., \& So, E. M. T. (2003). Prevalence estimates of problem and pathological gambling in Hong Kong. American Journal of Psychiatry, 160, 1353-1354.

Wong, I. L. K., \& So, E. M. T. (2004). A study of adolescent gambling behavior. Hong Kong: Hong Kong Polytechnic University. 